
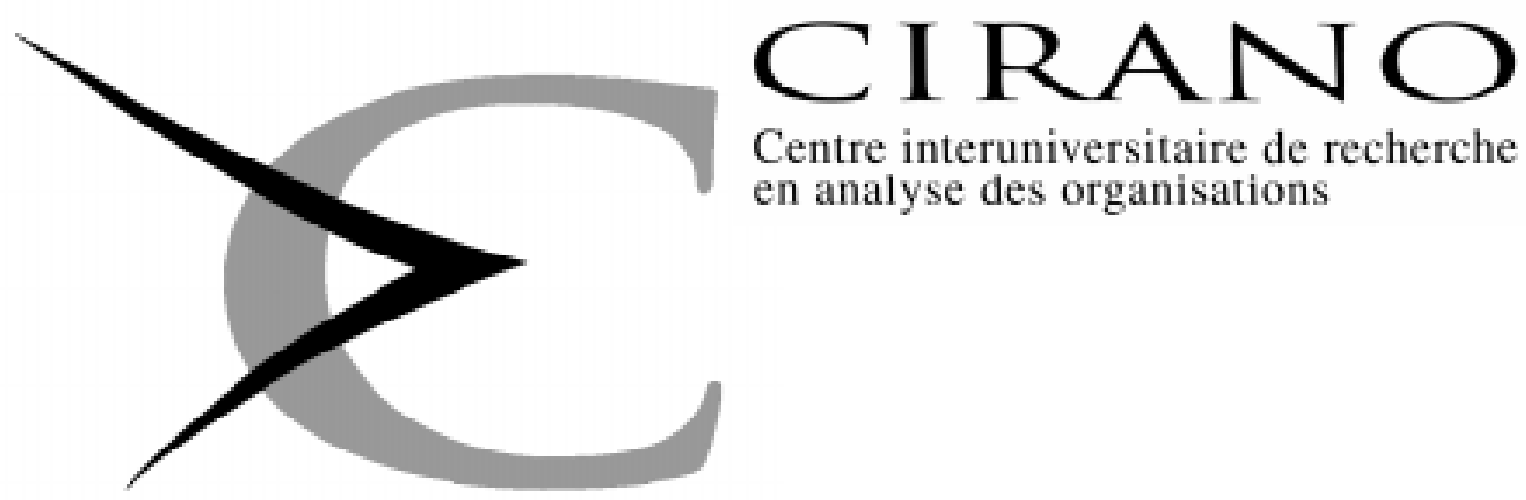

Centre interuniversitaire de recherche en analyse des organisations

Série Scientifique

Scientific Series

97s-32

Emerging Environmental Problems, Irreversible Remedies, and Myopia in a Two Country Setup

Marcel Boyer, Pierre Lasserre, Michel Moreaux 


\section{CIRANO}

Le CIRANO est une corporation privée à but non lucratif constituée en vertu de la Loi des compagnies du Québec. Le financement de son infrastructure et de ses activités de recherche provient des cotisations de ses organisations-membres, d'une subvention d'infrastructure du ministère de l'Industrie, du Commerce, de la Science et de la Technologie, de même que des subventions et mandats obtenus par ses équipes de recherche. La Série Scientifique est la réalisation d'une des missions que s'est données le CIRANO, soit de développer l'analyse scientifique des organisations et des comportements stratégiques.

CIRANO is a private non-profit organization incorporated under the Québec Companies Act. Its infrastructure and research activities are funded through fees paid by member organizations, an infrastructure grant from the Ministère de l'Industrie, du Commerce, de la Science et de la Technologie, and grants and research mandates obtained by its research teams. The Scientific Series fulfils one of the missions of CIRANO: to develop the scientific analysis of organizations and strategic behaviour.

\section{Les organisations-partenaires / The Partner Organizations}

-École des Hautes Études Commerciales

-École Polytechnique

-McGill University

-Université de Montréal

-Université du Québec à Montréal

-Université Laval

-MEQ

-MICST

-Avenor

-Banque Nationale du Canada

-Bell Québec

-Caisse de dépôt et placement du Québec

-Fédération des caisses populaires Desjardins de Montréal et de l'Ouest-du-Québec -Hydro-Québec

-Raymond, Chabot, Martin, Paré

-Scetauroute

-Société d'électrolyse et de chimie Alcan Ltée

-Téléglobe Canada

-Ville de Montréal

Ce document est publié dans l'intention de rendre accessibles les résultats préliminaires de la recherche effectuée au CIRANO, afin de susciter des échanges et des suggestions. Les idées et les opinions émises sont sous l'unique responsabilité des auteurs, et ne représentent pas nécessairement les positions du CIRANO ou de ses partenaires.

This paper presents preliminary research carried out at CIRANO and aims to encourage discussion and comment. The observations and viewpoints expressed are the sole responsibility of the authors. They do not necessarily represent positions of CIRANO or its partners.

ISSN 1198-8177 


\title{
Emerging Environmental Problems, Irreversible Remedies, and Myopia in a Two Country Setup*
}

\author{
Marcel Boyer ${ }^{\dagger}$, Pierre Lasserre ${ }^{\ddagger}$, Michel Moreaux ${ }^{\S}$
}

\section{Résumé / Abstract}

\begin{abstract}
Avec la croissance apparaissent de nouveaux besoins de protection de l'environnement. Nous étudions les règles d'investissement optimales lorsque les décisions sont irréversibles et les dépenses indivisibles. Une attitude myope consistant à ne prendre en compte que les données immédiates du problème sans considération des investissements futurs ni de ceux d'autres juridictions simplifie énormément l'analyse et mène dans certains cas aux décisions optimales. Dans un modèle à deux pays où chaque pays bénéficie des investissements de l'autre, la chronologie d'investissement choisie lorsque les pays doivent investir tour à tour constitue également un équilibre lorsque l'ordre d'intervention est endogène.
\end{abstract}

As development proceeds, the demand for environmental protection increases. We study optimal investment decision rules when protection investments are irreversible and indivisible. We show that myopia (focusing on one particular outlay without considering investments that are to come later in the sequence or are to be made by another jurisdiction) does not lead to errors in timing but greatly simplifies decision analysis. In a two country setup where each outlay benefits both countries, we also find that the equilibrium time sequence that arises when both countries must take turns to invest is also an equilibrium when the order is endogenous.

Mots Clés : Options réelles, investissement, environnement, externalité, myopie

Keywords : Real options, investment, environment, externality, myopia

\footnotetext{
* Corresponding Author: Marcel Boyer, CIRANO, 2020 University Street, 25th floor, Montréal, Qc, Canada H3A 2A5 Tel: (514) 985-4002 Fax: (514) 985-4035 e-mail: boyerm@cirano.umontreal.ca We thank Gérard Mondello and the participants in the Conference on "Dynamique industrielle et contraintes environnementales" organized by the LATAPSES at Sophia Antipolis, May 12 and 13, 1997. Financial support from FCAR (Québec), SSHRCC (Canada), and INRA (France) is gratefully acknowledged.

† École Polytechnique de Montréal, Université de Montréal and CIRANO

‡ Université du Québec à Montréal, GREQAM and CIRANO

$\S$ Institut Universitaire de France, Université de Toulouse, ERNA-INRA and IDEI
} 


\section{Introduction}

Imagine a finite world with increasing human activity and population. Some resources that were felt to be limitless progressively become scarcer. In some cases markets may establish themselves so that the resource becomes a tradable good or asset. Sometimes, especially in the early phase of the rarefaction process, transaction costs or other impediments prevent the existence of true markets.

Many environmental issues may be usefully analyzed within such a context. Thus air quality, water supply and quality, the climate, may be viewed as emerging goods, whose opportunity cost is not yet high enough to be fully incorporated into human activities, or whose opportunity cost has not been perceived high enough for institutions to be developped that would promote the internalization of that cost. In fact the whole Malthusian tradition which is so central to environmental economics revolves around the implications of growth and expansion.

This paper belongs to that tradition in that it models a growing environmental problem or, more precisely, the growing benefits from control or abatement actions. It will not focus on changing institutions however, but it introduces another feature which is often important in environmental problems: the irreversibility, and the indivisibility, of conservation or abatement investments. Thus the creation of a national park, the construction of a water purification plant, or the introduction of legislation protecting air quality are all investments of some magnitude that are, to a large extent, irreversible.

In fact the methodology used is that of real option theory, a field in which much research activity has been taking place recently (see in particular Dixit and Pindyck, 1994). In the resource literature, this interest dates back at least to Henry (1974), and Arrow and Fisher (1974). More recently, Baranzini et al (1994) applied real option theory to the problem of global warming, while Saphores and Conrad (1996) used that methodology to analyze pesticide spraying. Clearly the presence of uncertainty, combined with the magnitude and irreversibility of the investments involved in environmental protection make that methodology a prefered tool for the investigation of many environmental problems. It provides a tool for analyzing not only the desirability, but also the timing, of investments.

Although, to our knowledge, papers in the environmental field have focused on one particular investment decision, the real option literature has dealt extensively with successions of investments, options whose exercise open new options. We will consider a succession of investments here, focusing on their desirability and timing in the traditional fash- 
ion. We will also ask a more neglected question: to what extend is it necessary to know the sequence of future possible investments in order to make decisions with regard to the next candidate? This question is not usually considered in the real options literature because the option literature emphasizes option valuation. Clearly the value of a project which opens up a succession of new opportunities is not the same as the value of the same project, without the new opportunities it creates. However, in some circumstances, the date at which the project should be undertaken is the same in both cases. When this is true, the analysis of the investment decision may be simplified radically. Such is the case with the model presented below.

Our objective is to characterize optimal investment decision rules and to characterize the evolution of abatement or environment protection activities as development proceeds in a stochastic way, first under a centralized system, then when there are two competing jurisdictions. Such investment decisions involve the acquisition or exercise of real options. Exercizing such options amounts to giving up the opportunity to use future information, a cost that leads to a delay in the decision. ${ }^{1}$

In the next section, we present the model; in the following section we derive the socially optimal investment sequence and discuss some of its properties. Then, in Section 4, we introduce and solve a model involving two countries and an abatement externality.

\section{The model}

We envisage the development of an economy and the concomitant rise in an environmental problem. That problem may be mitigated by reducing the damage through specific irreversible investments which we normalize in such a way that each investment reduces damage by one unity or less. Thus if $x$ such unit investments have already been made, the associated damage reduction is $D(x)$ and its value to society, which depends on the state of development $Y(t)$ reached at date $t$ is $Y(t) \Phi(x(t))=$ $\int_{0}^{x(t)} Y(t) D(y) d y$. It may be thought of as the value of the consumer surplus arising from damage reduction. $Y(t)$ is positive and tends to

\footnotetext{
${ }^{1}$ As Abel, Dixit, Eberly and Pindyck (1996) illustrate with their generalized investment model, all those options need not in fact delay investments. In their model, firms can expand by acquiring new capital but possibly at a higher cost than its current one; this reduces the value of the call option that delaying investment carries and therefore it increases the current incentive to invest. The firm can also disinvest by selling some of its capital but possibly at a lower price than its original cost; this reduces the put option which investing now carries and which complete irreversibility ruled out, and therefore it reduces the current incentive to invest.
} 
grow over time. $D$ is strictly decreasing if positive, continuously differentiable on $\left(0, D^{-1}(0)\right)$, with $D^{-1}(0)=\lim _{p \rightarrow 0} D^{-1}(p)<\infty ; x D(x)$ is strictly concave on $\left(0, D^{-1}(0)\right)$.

Let $\bar{i}$ be the smallest integer equal to or higher than $D^{-1}(0)$. We assume that $\int_{0}^{1} D(x) d x<\infty$ and we define $\phi(i)$, the value (divided by $Y$ ) of the consumer surplus increment associated with the $i^{t h}$ abatement unit as

$$
\phi(i)=\left\{\begin{array}{c}
\int_{i-1}^{i} D(x) d x, i=1, \ldots, \bar{i}-1 \\
\int_{i-1}^{D^{-1}(0)} D(x) d x, i=\bar{i}
\end{array}\right.
$$

Note that $\Phi(i)=\sum_{1}^{i} \phi(j)$. Since $D$ is strictly decreasing

$$
\phi(1)>\phi(2)>\ldots>\phi(\bar{i})
$$

$Y$ follows a geometric Brownian motion

$$
d Y=\alpha Y d t+\sigma Y d z
$$

with $0<\alpha \leq r, r$ being the discount rate; $r-\alpha$ is defined as $\delta$. The perfect certainty case arises when $\sigma=0$, when $Y$ rises at the constant rate $\alpha$.

We will study situations where $Y$ is low initially and has never been high enough for any abatement capacity to be present, whatever the institutional context considered. The cost of each unit is $H$ in current value and is constant over time,

Society (countries) is (are) risk neutral and discount future revenues at rate $r$. Abatement units have no alternative use and do not depreciate. When we envisage the presence of two countries, we index them by $A$ and $B$, and we note $x=x_{A}+x_{B}$. We will alternatively consider and compare two types of behavior on the part of society or countries: perfect foresight, and myopia. By myopia we mean that countries ignore the influence on future benefits of both their own future actions and their competitors' future actions. However, unlike Leahy (1993) who considered atomistic, competitive, firms, a myopic country is assumed to take into account the current impact of its, and its competitors', actions.

\section{Socially optimal abatement capacity ac- quisition}

What is the socially optimal abatement capacity acquisition program in such a setup? It is possible to formulate the problem at hand in terms of 
the state variable $Y(t)$. Let $Y_{i}$ be the lowest value of the state variable at which the $i^{\text {th }}$ unit of abatement capacity must be acquired and $T_{i}$ as the date at which its acquisition occurs. By definition $T_{i} \leq T_{i+1}$, $i=1, \ldots \bar{i}$, and, obviously, $Y(0) \leq Y_{i} \leq \ldots \leq Y_{\bar{i}}$. The social planner's problem may be written as follows:

$$
\begin{aligned}
& \max _{Y_{1}, \ldots, Y_{\bar{i}}} E \quad\left\{\int_{0}^{\infty}\left[\int_{0}^{x(t)} e^{-r t} Y(t) D(z) d z\right] d t-\sum_{i=1}^{\bar{i}} e^{-r T_{i}} H\right\} \\
& \text { where }: \\
& \qquad \begin{aligned}
x(t) & =\left\{\begin{array}{c}
0 \quad \text { if } t<T_{1} \\
i \quad \text { if } T_{i} \leq t<T_{i+1}, \quad i=1, \ldots, \bar{i}-1 \\
D^{-1}(0) \quad \text { if } T_{\bar{i}} \leq t
\end{array}\right. \\
T_{i}= & \inf \left\{t \mid Y(t) \geq Y_{i}\right\} \quad i=1, \ldots \bar{i}
\end{aligned}
\end{aligned}
$$

Note that, if $T_{i}=T_{i+1},(3)$ implies that $x(t)$ is never equal to $i$ but jumps from $i-1$ or less to $i+1$ or more. Since $Y(t)$ is a stochastic process, $T_{i}$ is a random variable; hence in the objective function of (PS1), $E$ must be understood as the expected value taken over the $T_{i}$ 's given the $Y_{i}$ 's and the constraints of the problem.

$(P S 1)$ may be alternatively written as the following problem:

$$
\begin{aligned}
& \max _{Y_{1}} E\left\{\int_{T_{1}}^{\infty} e^{-r t} Y(t) \phi(1) d t-e^{-r T_{1}} H\right\} \\
& +\ldots+\max _{Y_{i}} E\left\{\int_{T_{i}}^{\infty} e^{-r t} Y(t) \phi(i) d t-e^{-r T_{i}} H\right\} \\
& +\ldots+\max _{Y_{\bar{i}}} E\left\{\int_{T_{\bar{i}}}^{\infty} e^{-r t} Y(t) \phi(\bar{i}) d t-e^{-r T_{\bar{i}}} H\right\}
\end{aligned}
$$

subject to (3) and (4)

Thus the planner's problem may be divided into a set of independent problems. For the $i^{t h}$ problem, the solution takes the form of a rule stating that the $i^{\text {th }}$ unit of abatement capacity must be acquired when $Y$ reaches $Y_{i}$ for the first time, at $T_{i}$. Let $m(Y, i)$ be the welfare function associated with that sub-problem. Since $E\left\{\int_{T_{i}}^{\infty} e^{-r t} Y(t) \phi(i) d t\right\}=$ $E\left\{e^{-r T_{i}} \frac{Y_{i} \phi(i)}{\delta}\right\}$,

$$
m(Y, i)=\max _{Y_{i}} E\left\{e^{-r T_{i}}\left[\frac{Y_{i} \phi(i)}{\delta}-H\right] \mid T_{i}=\inf \left\{t \mid Y(t) \geq Y_{i}\right\}\right\}
$$


Problem (6) is a stochastic dynamic programming problem. When $Y$ is (and has always been) sufficiently low that the $i^{\text {th }}$ unit has not been acquired yet and is not to be acquired in the next interval $d t$, Bellman's equation is $m_{Y} \alpha Y+\frac{1}{2} m_{Y Y} \sigma^{2} Y^{2}-r m=0$. Given that $m$ must vanish if $Y$ goes to zero, its solution is $B_{i} Y^{b}$ where $b$ is the positive root of the quadratic equation:

$$
Q(y)=.5 \sigma^{2} y[y-1]+\alpha y-r=0
$$

The constant $B_{i}$ may be found by invoking the value matching and smooth pasting conditions; these conditions imply

$$
\begin{aligned}
Y_{i S} & =\frac{H \delta}{\phi(i)} \frac{b}{b-1} \\
B_{i S} & =\left[\frac{\phi(i)}{\delta b}\right]^{b}\left(\frac{b-1}{H}\right)^{1-b} \\
m^{S}(Y, i) & =\left[\frac{\phi(i)}{\delta b}\right]^{b}\left(\frac{b-1}{H}\right)^{1-b} Y^{b}
\end{aligned}
$$

where again the subscript $S$ refers to a social optimum. According to (8), at the date of the investment, the value of the cumulative surplus generated by the new unit, capitalized at the discount rate $r$, exceeds the cost of acquiring that unit. Equations (1) and (10) also imply that $m^{S}$ is decreasing in $i$ : the value to society of the option to invest one day in the $i^{t h}$ abatement capacity unit is decreasing in $i$.

The presence of uncertainty has the effect that investing now implies giving up the possibility to use future information. Consequently the threshold value $Y_{i S}$ may be shown to be higher than under certainty and to increase with $\sigma$. In fact, since $b$ is the positive root of (7), it can be shown, replacing $\alpha$ by $r-\delta$, that $\delta \frac{b}{b-1}=r+\frac{1}{2} \sigma^{2} b$. Thus (8) may be written as $Y_{i S} \phi(i)=H\left[r+\frac{1}{2} \sigma^{2} b\right]$, which means that the proper notion of user cost is $r$ (as under certainty) augmented with the rental value to society of remaining flexible $\frac{1}{2} \sigma^{2} b$.

Now imagine that the social planner is myopic in the sense mentioned earlier: she does not consider any action beyond her current decision. Facing the decision to acquire the $i^{\text {th }}$ abatement capacity unit, such a myopic social planner solves

$\max _{Y_{i}} E \int_{T_{i}}^{\infty} e^{-r t} Y(t) \phi(i) d t-e^{-r T_{i}} H$ subject to $T_{i}=\inf \left\{t \mid Y(t) \geq Y_{i}\right\}$ 
instead of

$$
\begin{aligned}
\max _{Y_{i}, \ldots, Y_{\bar{i}}} & E\left\{\left\{\int_{0}^{\infty}\left[\int_{0}^{x(t)} e^{-r t} Y(t) D(z) d z\right] d t-\sum_{j=i}^{\bar{i}} e^{-r T_{j}} H\right\}\right. \\
\text { subject to } T_{j} & =\inf \left\{t \mid Y(t) \geq Y_{j}\right\}, j=i, \ldots, \bar{i}
\end{aligned}
$$

As was shown above, the complete problem is separable into components such as problem (11). Consequently, the solution $Y_{i S}$ of (11) is part of the non myopic solution. The myopic social planner would understate society's welfare if it used the solution of (11) to evaluate it, thus ignoring the subsequent abatement options, but she would time the investment correctly. Thus the following proposition.

Proposition 1 By using a myopic abatement rule, a social planner invests in the best interest of society, although it understates society's welfare.

This result is reminiscent of a similar result established by Leahy (1993) for competitive firms with indefinitely divisible capital. Its intuition is the same: by being myopic, the country underestimates by the same amount the value of its option to remain flexible, and the marginal benefit from investing. This leaves the investment rule unaffected.

\section{The two-country case}

In this section we examine what happens if the environmental damage affects two countries, A and B, while the cost of abatement is born by whichever country invests in the abatement measure. Although this may also be modelled as a partial externality we focus on the pure externality case. Thus the benefits from each damage reduction are equally shared by both countries, while the cost is born by that country which implements the damage reduction measure. Strategic behavior may occur as it is in each country's interest to let the other bear the cost. But there may be differences in outcomes depending on the institutional constraints and on the technological framework under which the countries operate. In particular we will consider two alternative situations: when each abatement decision in the sequence is unambiguously identified with one of the two countries; and when each investment may be made by one country or the other indifferently. We start with the first alternative. 


\subsection{Case 1: Exogenously given investment sequence}

In order to clarify the exposition, we assume that abatement decisions alternate between countries, with A having to make the first one. We also assume that no country may skip its turn so that, for example, A cannot introduce its second abatement measure before B has implemented its first one.

We define a country's welfare as the expected cumulative flow of abatement benefits, discounted to the current date, net of the expected discounted abatement costs that the country will incur in the future. Let $W^{A}\left(Y, i_{A} ; i_{B}\right)$ be the welfare of country $A$ when it holds $i_{A}$ units of abatement capacity while the other country holds $i_{B}$ units. Given the assumptions on $D(x)$, there are maxima $\bar{i}_{A}$ and $\bar{i}_{B}$ to the number of units that each country will ever consider acquiring, so that $i_{A} \in I_{A}=\left\{1,3, \ldots, \bar{i}_{A}\right\}$ and $i_{B} \in I_{B}=\left\{2,4, \ldots, \bar{i}_{B}\right\}$, with $\bar{i}_{A}+\bar{i}_{B}=\bar{i}$. Assuming that both countries share equally in the benefits from damage reduction

$$
\begin{gathered}
W^{A}(Y, 0 ; 0)= \\
\max _{Y_{i}, i \in I_{A}} E\left\{\frac{1}{2} \int_{0}^{\infty}\left[\int_{0}^{x(t)} e^{-r t} Y(t) D(z) d z\right] d t-\sum_{i \in I_{A}} e^{-r T_{i}} H\right\}(C A)
\end{gathered}
$$

where :

$$
\begin{aligned}
x(t) & =\left\{\begin{array}{l}
0 \quad \text { if } t<T_{1} \\
i \quad \text { if } T_{i} \leq t<T_{i+1}, \quad i=1, \ldots, \bar{i}-1 \\
D^{-1}(0) \quad \text { if } T_{\bar{i}} \leq t
\end{array}\right. \\
T_{i} & =\inf \left\{t \mid Y(t) \geq Y_{i}\right\} \quad i \in I_{A}
\end{aligned}
$$

For $i \in I_{B} Y_{i}$ is defined by the converse problem, which defines $W^{B}(Y, 0,0)$.

We start with a particular case where each country is constrained to a maximum abatement capacity of one. Thus consider a situation at date $t$ where country A already holds its abatement unit while the other country does not. Their current welfare functions are $W^{A}(Y, 1 ; 0)$ and $W^{B}(Y, 0 ; 1)$. It is B's turn to make an abatement decision: B must find $Y_{2}$ the value of $Y$ at which it should invest. ${ }^{2}$ The solution also defines $\mathrm{B}$ 's welfare from $t$ onward

$$
\begin{aligned}
W^{B}(Y, 0,1) & =\max _{Y_{2}} E_{t}\left\{\frac{1}{2} \int_{t}^{T_{2}} e^{-r[\tau-t]} Y(\tau) \Phi(1) d \tau\right. \\
& \left.+e^{-r\left[T_{2}-t\right]}\left[W^{B}\left(Y_{2}, 1,1\right)-H\right]\right\}
\end{aligned}
$$

\footnotetext{
${ }^{2}$ It must be the case that $Y$ has already reached $Y_{1}$ at least once and has never reached $Y_{2}$.
} 
where the welfare of $\mathrm{B}$ once it has acquired its abatement capacity is

$$
W^{B}(Y, 1,1)=\frac{1}{2} \frac{Y \Phi(2)}{\delta}=W^{A}(Y, 1,1)
$$

The second equality in (13) indicates that A's welfare is the same as B's once the last abatement decision has been implemented by B.

In order to solve $(C B)$, let us decompose $W^{B}$ as $W^{B}(Y(t), 0,1)=$ $Y(t) \frac{1}{2} \Phi(1) d t+E_{t}\left\{e^{-r d t} W^{B}(Y(t+d t), 0,1)\right\}$, which, after expanding $e^{-r d t} W^{B}(Y(1+d t), 0,1)$ around $W^{B}(Y(t), 0,1)$, applying Ito's lemma and some manipulations, gives (we omit the ${ }^{B}$ exponent and function arguments when no ambiguity may arise)

$$
\frac{1}{2} \Phi(1) Y+W_{Y} \alpha Y+\frac{1}{2} W_{Y Y} \sigma^{2} Y^{2}-r W=0
$$

The general solution of this non homogenous linear differential equation is $W=B_{2} Y^{b}+\bar{B} Y^{\bar{b}}+\frac{\frac{1}{2} \Phi(1) Y}{\delta}$ where $\frac{\frac{1}{2} \Phi(1) Y}{\delta}$ is a particular solution and $B_{2} Y^{b}+\bar{B} Y^{\bar{b}}$ is the solution to the homogenous part of the equation. The constant $\bar{B}$ must be null if the value of the welfare function is to vanish when $Y$ goes to zero; consequently the solution must be of the form $W^{B}(Y, 1,0)=B_{2} Y^{b}+\frac{\frac{1}{2} \Phi(1) Y}{\delta}$. One notes that $\frac{\frac{1}{2} \Phi(1) Y}{\delta}$ is the expected value of B's cumulated welfare if abatement capacity stays at 1 forever, i.e. if $\mathrm{B}$ never invests; consequently, $B_{2} Y^{b}$ must represent the impact of B's investment option on B's welfare. In order to determine $B_{2}$ one has to use the value matching and smooth pasting conditions. At $Y_{2}$, when $\mathrm{B}$ invests, the value matching condition is $W^{B}\left(Y_{2}, 0,1\right)=W^{B}\left(Y_{2}, 1,1\right)-H$ or

$$
B_{2} Y_{2}^{b}+\frac{1}{2} \frac{Y_{2} \Phi(1)}{\delta}=\frac{1}{2} \frac{Y_{2} \Phi(2)}{\delta}-H
$$

The smooth pasting condition is $W_{Y}^{B}\left(Y_{2}, 0,1\right)=W_{Y}^{B}\left(Y_{2}, 1,1\right)$ implying

$$
B_{2} b Y_{2}^{b}+\frac{1}{2} \frac{Y_{2} \Phi(1)}{\delta}=\frac{1}{2} \frac{Y_{2} \Phi(2)}{\delta}
$$

Since $\Phi(2)-\Phi(1)=\phi(2)$, it follows that

$$
\begin{gathered}
Y_{2 X}=\frac{H \delta}{\frac{1}{2} \phi(2)} \frac{b}{b-1} \\
B_{2 X}=\left[\frac{\frac{1}{2} \phi(2)}{\delta b}\right]^{b}\left[\frac{b-1}{H}\right]^{b-1}
\end{gathered}
$$


where the ' $X$ ' subscript refers to the exogeneity of the investment sequence assumed in case 1. A comparison with (8) and (9), taken at $i=2$, reveals that $Y_{2 X}=2 Y_{2 S}$ and $B_{2 X}=\left[\frac{1}{2}\right]^{b} B_{2 S}$ : the second investment occurs later, at a development level twice higher, than is socially desirable, and, since $b>1$, it can be shown that the welfare achieved by $\mathrm{B}$ is less than half the combined welfare of $\mathrm{A}$ and $\mathrm{B}$ under the socially optimal scheme at the same level of $Y$ (chosen, for comparison purposes, such that the second investment has not occurred under the socially optimal scheme or under the conditions of case 2 .

Now consider country A's problem when A knows that B cannot make any move before $\mathrm{A}$ has acquired its abatement unit:

$$
W^{A}(Y, 0 ; 0)=\max _{Y_{1}} E_{t}\left\{e^{-r\left[T_{1}-t\right]}\left[W^{A}\left(Y_{1}, 1 ; 0\right)-H\right]\right\}
$$

where, for $T_{1} \leq \tau \leq T_{2}$

$$
W^{A}(Y, 1 ; 0)=E_{\tau}\left\{\int_{\tau}^{T_{2}} e^{-r[t-\tau]} \frac{1}{2} Y(t) \Phi(1) d t+e^{-r\left[T_{2}-\tau\right]} \frac{\frac{1}{2} Y_{2} \Phi(2)}{\delta}\right\}
$$

The first term in the expected value corresponds to benefits that $\mathrm{A}$ shares with B until B's abatement investment occurs; the second term corresponds to the period following B's investment.

One notes that, unlike previous expected welfare functions which were defined by some maximization problem, there is no decision involved in the definition of $W^{A}(Y, 1 ; 0)$; the investment in the second abatement unit is B's, not A's, decision. Nevertheless let us apply to the right-hand side of (20) the same treatment as is done in dynamic programming problems in order to establish Bellman's equation. Assuming that $Y$ is low enough for B not to enter in the next interval $d t$, let us decompose $W^{A}$ as $W^{A}(Y, 1 ; 0)=Y(t) \frac{1}{2} \Phi(1) d t+E_{0}\left\{e^{-r d t} W^{A}(Y(0+d t), 1 ; 0)\right\}$, which, after expanding $e^{-r d t} W^{A}(Y(0+d t), 1 ; 0)$ around $W^{A}(Y(0), 1 ; 0)$, applying Ito's lemma and some manipulations, gives (we omit the ${ }^{A}$ exponent until ambiguity may arise)

$$
\frac{1}{2} Y \Phi(1)+W_{Y} \alpha Y+\frac{1}{2} W_{Y Y} \sigma^{2} Y^{2}-r W=0
$$

This differential equation is the same as the one found to be satisfied by $W^{B}(Y, 0,1)$ (see (14)). As the latter, its solution is of the form $W(Y, 1 ; 0)=\beta_{1} Y^{b}+\frac{Y \frac{1}{2} \Phi(1)}{\delta}$; the term $\frac{Y \frac{1}{2} \Phi(1)}{\delta}$ is A's expected cumulated welfare if abatment capacity stays at 1 forever, i.e. if $\mathrm{B}$ never invests; consequently, $\beta_{1} Y^{b}$ must represent the impact on A's value 
of B's investment; however, unlike the case of B, since (20) does not involve an optimization, there are no value matching or smooth pasting conditions to determine $\beta_{1}$ and $Y_{1}$. In order to find these parameters, let us proceed from the following remark. As already noted, at $Y_{2 X}$, just after the entry of $\mathrm{B}, \mathrm{A}$ and $\mathrm{B}$ have the same welfare (they have the same abatement capacity and share the same benefits equally): $W^{B}(Y, 1 ; 1)=W^{A}(Y, 1 ; 1)=\frac{\frac{1}{2} \Phi(2) Y}{\delta}$. Furthermore, since the entry of $\mathrm{B}$ is anticipated, the welfare of A does not jump at B's entry: $W^{A}\left(Y_{2}, 1 ; 0\right)=W^{A}\left(Y_{2}, 1 ; 1\right)$. Substituting explicit forms one has

$$
\beta_{1} Y_{2}^{b}+\frac{Y_{2} \frac{1}{2} \Phi(1)}{\delta}=\frac{Y_{2} \frac{1}{2} \Phi(2)}{\delta}
$$

Substituting (17) for $Y_{2}$ gives

$$
\beta_{1}=b\left[\frac{b-1}{H}\right]^{b-1}\left[\frac{\frac{1}{2} \phi(2)}{\delta b}\right]^{b}
$$

Having established that $W^{A}(Y, 1 ; 0)=\beta_{1} Y^{b}+\frac{Y \frac{1}{2} \Phi(1)}{\delta}$, we may now study the entry decision of A, problem (19). This problem differs from $(C B)$ in that the firm does not enjoy any welfare flow while waiting to invest into abatement capacity. As a result Bellman's equation is homogenous and its solution is $B_{1} Y^{b}$ where $B_{1}$ is to be determined from the value matching and smooth pasting conditions

$$
\begin{aligned}
B_{1} Y_{1}^{b} & =\beta_{1} Y_{1}^{b}+\frac{Y_{1} \frac{1}{2} \Phi(1)}{\delta}-H \\
b B_{1} Y_{1}^{b-1} & =b \beta_{1} Y_{1}^{b-1}+\frac{\frac{1}{2} \Phi(1)}{\delta}
\end{aligned}
$$

These conditions imply, since $\Phi(1)=\phi(1)$

$$
\begin{aligned}
Y_{1 X} & =\frac{H \delta}{\frac{1}{2} \phi(1)} \frac{b}{b-1} \\
B_{1 X} & =\beta_{1}+\left[\frac{b-1}{H}\right]^{b-1}\left[\frac{\frac{1}{2} \phi(1)}{\delta b}\right]^{b} \\
& =\left[\frac{b-1}{H}\right]^{b-1}\left[b\left[\frac{\frac{1}{2} \phi(2)}{\delta b}\right]^{b}+\left[\frac{\frac{1}{2} \phi(1)}{\delta b}\right]^{b}\right]
\end{aligned}
$$

where, again, the $X$ subscript has been added to refer to the exogeneity of the abatement investment sequence. Thus, according to (25), the first 
abatement investment also occurs at a level of $Y$ twice higher than is socially optimal and, as a result, welfare is lower than would be socially possible.

It is simple, perhaps somewhat tedious, to extend this two-country model to cases where each country has the possibility to invest in any number of abatement capacity units in alternating (or exogenously given) order. The procedure requires finding the maximum number of abatement units that will be introduced by each country (such a maximum exists under the assumptions made on $D(x)$ ) and then establishing the welfare functions in backward chronological order as above.

Now suppose that countries A and B are myopic in the sense mentioned earlier: when considering the introduction of an abatement measure, each country ignores any subsequent abatement decision that it, or the other country, may take in the future. Thus, going back to the simple case solved above where each country may invest at most once, country A, when studying its abatement decision, instead of solving $(C B)$, will solve

$$
\max _{Y_{1}} E\left\{\int_{T_{1}}^{\infty} e^{-r t} Y(t) \frac{1}{2} \Phi(1) d t-e^{-r T_{1}} H\right\}
$$

More generally, in the absence of any constraint on the number of abatement decisions, a myopic country would consider that problem instead of problem $(C A)$ and a similar simplication would apply to the choice of any subsequent abatement investment. Solving $(C B)$ one finds that the option to invest in the first abatement unit, when evaluated that way, is worth $B_{1 x} Y^{b}$ and

$$
\begin{aligned}
Y_{1 x} & =\frac{H \delta}{\frac{1}{2} \Phi(1)} \frac{b}{b-1} \\
B_{1 x} & =\left[\frac{\frac{1}{2} \Phi(1)}{\delta b}\right]^{b}\left[\frac{b-1}{H}\right]^{b-1}
\end{aligned}
$$

where the ' $x$ ' subscript refers to the exogeneity of the abatement investments sequence, but in a context of myopic decisions. While $B_{1 x}<B_{1 X}$, which implies that its myopia leads the country to underestimate its welfare by neglecting to take account of subsequent options, $Y_{1 x}=Y_{1 X}$, implying that the myopia has no effect on the investment timing. This result may be generalized to situations where the countries do not face any abatement capacity limit.

Finally, it is interesting to note that B's welfare is higher than A's. This result can be explained by the fact that both countries enjoy the same flow of amenities derived from abatement measures, but differ by 
the timing of their expenditures. The country which gets to invest later enjoys a higher welfare.

The results applying to case 1 are gathered into the following proposition.

Proposition 2 In the two country model with exogenously given investment sequence:

1. each abatement capacity unit is acquired later than is socially desirable;

2. if they use a myopic investment rule, the countries make the same decisions as if they addressed the complete investment sequencing problem with foresight; however, by so doing they understate the welfare gains to be expected from future abatement actions.

3. The country which gets to invest the latest enjoys the highest welfare.

\subsection{Case 2: Endogenous investment sequence}

If the order in which the countries make their expenditures is endogenous, one might expect each country to try to avoid adopting any abatement measure, in the hope that the other country will do it instead. By so doing a country would hope to get the benefits of abatement at no cost. Consider again the simple case of two countries and a maximum total number of two abatement investments. Any one of the two countries may invest 0,1 , or 2 units in any order.

Without getting involved into the formal analysis, it is possible to describe the pure strategy equilibria of that game. ${ }^{3}$ First note that a strategy consisting, for each country, in never investing whatever the other country does, cannot be an equilibrium. A slight modification of the analysis presented in Case 1 shows that, when $Y$ reaches $Y_{1 X}$ not investing is not be a best response by A to a strategy of never investing by B.

Now consider the following pair of pure strategies for A and B. For A, invest one unit if $Y \geq Y_{1 X}$ and no unit has yet been installed; and do not invest otherwise. For B, invest one unit if $Y \geq Y_{2 X}$ and the number of installed units is less than 2; and do not invest otherwise. It is easy to check that this pair of pure strategies yields a Nash equilibrium to any subgame starting at any $t \geq 0$ with any combination of $Y$ and of

\footnotetext{
${ }^{3}$ For a treatment of mixed strategy equilibria in the spirit of the present study, see the duopoly model of Boyer, Lasserre, and Moreaux (1997).
} 
$i_{A} \in\{0,1,2\}, i_{B} \in\{0,1,2\}$ such that $i_{A}+i_{B} \leq 2$. Thus the equilibrium described in the previous case remains a (sub-game perfect) equilibrium when the sequence of investments is endogenous.

However this is not the only Nash equilibrium: inverting the roles of A and $\mathrm{B}$ yields another one. More interestingly, a third sub-game perfect equilibrium results from a strategy of never investing by $\mathrm{B}$, combined with the following strategy for A: if $Y_{2 X}>Y \geq Y_{1 X}$ and no unit has yet been installed, then invest one unit, and do not invest otherwise; if $Y \geq Y_{2 X}$ then invest either one unit if one unit has already been installed, or invest two units if no unit has yet been installed, and do not invest otherwise. In that equilibrium, A pays all the costs while B free rides happily.

This generalizes to cases involving a limitless number of abatement investments.

\section{Concluding Remarks}

In this paper, we have presented and analyzed a model of economic expansion with rising environmental problems. These problems give rise to a demand for abatement or control, which in turn provides investment opportunities in these areas. We have focused on investments such as the creation of national parks and protected areas or the introduction of antipollution standards, i.e. on decisions characterized by their irreversibility, their indivisibility, and the public good nature of their consequences. To be socially optimal, these investments must be sequenced in such a way that each of them occurs when the level of development has reached some critical value. At that time, the expected discounted present value of the benefits from the investment must be strictly higher than the cost of the investment. An efficient environmental policy requires abatement measures to be taken early enough. However one should not intervene too early: as we have shown, at the time of investment, the benefits from the abatement must strictly exceed the cost of the intervention. This result is not due to the uncertainty surrounding the decision; in fact it holds even in the absence of such uncertainty, although uncertainty increases the spread between expected discounted present value and cost.

Not surprisingly, when two countries share the benefits, but not the costs, of the abatement investments, these investments occur later than is socially optimum. More surprisingly, within the social optimization model as well as in the Nash equilibrium framework of the two-country model, the level of development at which a particular investment is called 
for is the same whether the decision maker(s) behave(s) myopically, ignoring all decisions to be taken in the future, or consider(s) and evaluate(s) the whole sequence of subsequent investments.

Extensions to situations when the positive externality from abatement is not pure, i.e. to situations where the country that invests benefits more than the other country are left for a sequel. One may conjecture that, in such situations, the desire to preempt might offset the temptation to free ride, so that the abatement investment sequence might not be too conservative despite the externality. 


\section{References}

[1] Abel, A. B. A. K. Dixit, J. C. Eberly, and R. S. Pindyck (1995), "Options, the value of Capital, and Investment", Discussion Paper Nr. 15-95, Rodney White Center for Financial Research, Wharton School, University of Pennsylvania, Philadelphia.

[2] Arrow, K.J. (1968), "Optimal Capital Policy with Irreversible Investment", in J.N. Wolfe, ed., Value, Capital, and Growth: Papers in Honour of Sir John Hicks (Edinburgh: Edinburgh University Press), 1-19.

[3] Baranzini, A., M. Chesney, and J. Morisset (1994) "Uncertainty and Global Warming Policy" Cahier No 94.09, Département d'économie politique, Université de Genève.

[4] Boyer, M., P. Lasserre, and M. Moreaux (1997) "Industry Development Under Alternative Market Structures", communication to the European Summer Meeting of the Econometric Society, Toulouse, August 27-28.

[5] Coggins, J. S. and C. A. Ramezani (1996), "An Arbitrage-free Approach to Quasi-Option Value", mimeo., University of Minnesota.

[6] Dixit, A.K. (1992), "Investment and Hysteresis", Journal of Economic Perspectives, VI, 107-32.

[7] Dixit, A.K. and R.S. Pindyck (1994), Investment under Uncertainty, Princeton University Press, Princeton.

[8] Freixas, X. and J.J. Laffont (1984), "On the Irreversibility Effect", ch.7 (pp. 105-114) in Bayesian Models in Economic Theory, (Marcel Boyer and Richard E. Kihlstrom, eds.), North-Holland.

[9] Leahy, J.V. (1994), "Investment in Competitive Equilibrium: the Optimality of Myopic Behavior", Quaterly Journal of Economics, CIV, 1105-1133.

[10] Pindyck, R.S. (1991), "Irreversibility, Uncertainty, and Investment", Journal of Economic Literature, XXIX, 1110-52.

[11] Saphores, J.-D. and J. Conrad (1996) "Modéliser l'usage d'un pesticide comme une option financière: une application à l'acarien rouge" mimeo, Journées du Green, Université Laval, Québec. 


\section{Liste des publications au CIRANO .}

\section{Cahiers CIRANO / CIRANO Papers (ISSN 1198-8169)}

96c-1 Peut-on créer des emplois en réglementant le temps de travail ? / Robert Lacroix

95c-2 Anomalies de marché et sélection des titres au Canada / Richard Guay, Jean-François L'Her et Jean-Marc Suret

95c-1 La réglementation incitative / Marcel Boyer

94c-3 L'importance relative des gouvernements : causes, conséquences et organisations alternative / Claude Montmarquette

94c-2 Commercial Bankruptcy and Financial Reorganization in Canada / Jocelyn Martel

94c-1 Faire ou faire faire : La perspective de l'économie des organisations / Michel Patry

Série Scientifique / Scientific Series (ISSN 1198-8177)

97s-34 Do Canadian Firms Respond to Fiscal Incentives to Research and Development? / Marcel Dagenais, Pierre Mohnen et Pierre Therrien

97s-33 A Semi-Parametric Factor Model of Interest Rates and Tests of the Affine Term Structure / Eric Ghysels et Serena Ng

97s-32 Emerging Environmental Problems, Irreversible Remedies, and Myopia in a Two Country Setup / Marcel Boyer, Pierre Lasserre et Michel Moreaux

97s-31 On the Elasticity of Effort for Piece Rates: Evidence from the British Columbia Tree-Planting Industry / Harry J. Paarsch et Bruce S. Shearer

97s-30 Taxation or Regulation: Looking for a Good Anti-Smoking Policy / Paul Leclair et Paul Lanoie

97s-29 Optimal Trading Mechanisms with Ex Ante Unidentified Traders / Hu Lu et Jacques Robert

97s-28 Are Underground Workers More Likely To Be Underground Consumers? / Bernard Fortin, Guy Lacroix et Claude Montmarquette

97s-27 Analyse des rapports entre donneurs d'ordres et sous-traitants de l'industrie aérospatiale nord-américaine / Mario Bourgault

97s-26 Industrie aérospatiale nord-américaine et performance des sous-traitants : Écarts entre le Canada et les États-Unis / Mario Bourgault

97s-25 Welfare Benefits, Minimum Wage Rate and the Duration of Welfare Spells: Evidence from a Natural Experiment in Canada / Bernard Fortin et Guy Lacroix

97s-24 Incentive Effects of Public Insurance Programs on the Occurence and the Composition of Workplace Injuries / Denis Bolduc, Bernard Fortin, France Labrecque et Paul Lanoie

\footnotetext{
* Vous pouvez consulter la liste complète des publications du CIRANO et les publications elles-mêmes sur notre site World Wide Web à l'adresse suivante :

http://www.cirano.umontreal.ca/publication/page1.html
} 